\title{
When Words Alone Don't Speak: Preliminary Findings from a Higher Education Program with Innovative Delivery Technologies
}

\author{
Christopher Klopper ${ }^{\mathrm{a}}$, Wendi Beamish ${ }^{\mathrm{b}}$, and Helen Klieve ${ }^{\mathrm{c}}$ \\ Griffith Institute for Educational Research, Griffith University, Queensland, Australia \\ ${ }^{a}$ c.klopper@griffith.edu.au, bw.beamish@griffith.edu.au, ch.klieve@griffith.edu.au
}

Keywords: instructional delivery technologies, Australian sign language, deaf education

\begin{abstract}
Sign bilingual education, as an approach to the education of deaf children, has been recognised in Australia for many years. The effective implementation of this approach requires teachers to have a sound linguistic knowledge and communicative competence in Australian Sign Language (Auslan), as well as an understanding of current theory and research in pedagogical practices. This paper explores preliminary findings of a case study that utilised design-based research to deliver a specialised program in Australian Sign Language Studies to a group of teachers and teaching assistants working with deaf students throughout the state of Queensland, Australia. Findings reveal that the use of technology was a facilitating factor in the student's learning rather than an objective of learning. The approach utilised highlights the pedagogical possibilities that delivery technologies for learning offer in Higher Education.
\end{abstract}

\section{Introduction}

The growing importance of educational design recognises that students' needs are becoming more diverse, that teaching staff are under increasing pressure to provide better education with fewer resources, and that employers' expectations of graduates are not diminishing. This research project grew out of the need for the Queensland Department of Education and Training (DET) to upskill more staff (teachers and teaching assistants) in order to meet demands for educating deaf students across the state, particularly in rural areas. DET had already contracted Griffith University to deliver an Australian Sign Language (Auslan) program on two previous occasions, but online course development and learning had advanced substantially since the last offering in 2010 [1].

Griffith University, in common with many universities across Australia and internationally, utilises virtual learning platforms or Learning Management Systems (LMS) that provide the web-based framework to handle all online aspects of the learning process. Blackboard and WebCT are well-known examples of LMS that provide additional functionality beyond providing instructional content because they are also the portal for interactive technologies such as virtual classrooms, facilitation of assessment processes, the integration of databases across the entire system and they can track and personalise individual student learning. These systems provide access to a range of instructional delivery technologies such as discussion boards, mail systems, live chat, lecture recordings and podcasting along with other course resources [2]. A major goal of utilising these systems is to cater to a more diverse student population and enhance the quality of their university experience while simultaneously aiming to reduce the costs associated with delivering a high standard of tertiary education.

The study adopted a design-based research approach [3] with the aim to analyse learning in specific educational contexts through the systematic design and study of delivery technologies and pedagogical possibilities. It is argued that design-based research can assist in the creation and extension of knowledge "about developing, enacting, and sustaining innovative learning environments" (p. 5). The Design-based Research Collective emphasise the value of attending to the educational context, claiming it “...is not simple but it produces a better understanding of an intervention, and it can lead to improved theoretical accounts of teaching and learning" (p. 7). There is no single design-based research method, but rather an explicit overarching concern for using 
methods that link the processes of enactment to learning outcomes and this has the potential to generate knowledge that directly applies to efficacy of educational practice [4].

\section{Pedagogical Possibilities: A description of the program}

Sign bilingual education as an approach to the education of deaf children, has been recognised in both educational policy and practice in Australia for many years [5]. The effective implementation of this approach requires teachers to have a sound linguistic knowledge and communicative competence in Auslan, as well as an understanding of current theory and research in pedagogical practices. The purpose of the program was to upskill geographically isolated teachers and teaching assistants in instructional proficiency and understanding the role of Auslan as the language of instruction for deaf.

The program was executed over two years across four consecutive teaching periods of 13 weeks and consisted of four courses (Auslan 1 through 4) with the content and sequence developed to reflect the progressive nature of language learning. This in turn extended into forms of pedagogy and curriculum design. These elements provided both broad and specific features for understanding the applications of the language in schools. Participating staff were introduced to the core design features of the language: grammar, central elements of sign formation, expressive and receptive use of the language, sociolinguistic variations and considerations of situational factors in sign language use. Expressive and receptive practice with the language was maintained throughout each of the courses. In addition, procedures for continuous assessment and feedback were included to support and enhance student learning and the development of proficiency was provided. The first three courses afforded participating staff one day per week of release from their schools in order to engage in a combination of lectures, tutorials, and independent study. These activities were delivered via a mix of face-to-face, videoconferencing, and on-line delivery modes. For these courses the teaching period culminated in a face-to-face intensive period of language exposure and practice, using language "immersion" techniques as well as explicit teaching of linguistic features and structures. The final course afforded staff one day per week of release across the teaching period to design and implement an action research project in schools as summative assessment.

\section{Results}

The study followed a five-stage iterative process commencing with baseline data collection at the start of the program and then sequentially at the end of each course. All data was collected by means of online survey. At collection point one, all participating staff $[n=26]$ were asked to respond to items concerning computer efficacy, attitudes, and technology-related anxieties adopted from The Computer Technology Use Scale (CTUS) [6]. Fig. 1 identifies a number of items from initial responses to the CTUS. A notable level of agreement was indicated on the item regarding the need for time and persistance in getting familiar with computer systems (mean 5.55). Staff also agreed with the statement that they could use help structures to sort out problems (mean 4.77), which suggested an overall level of basic computer technology competence.

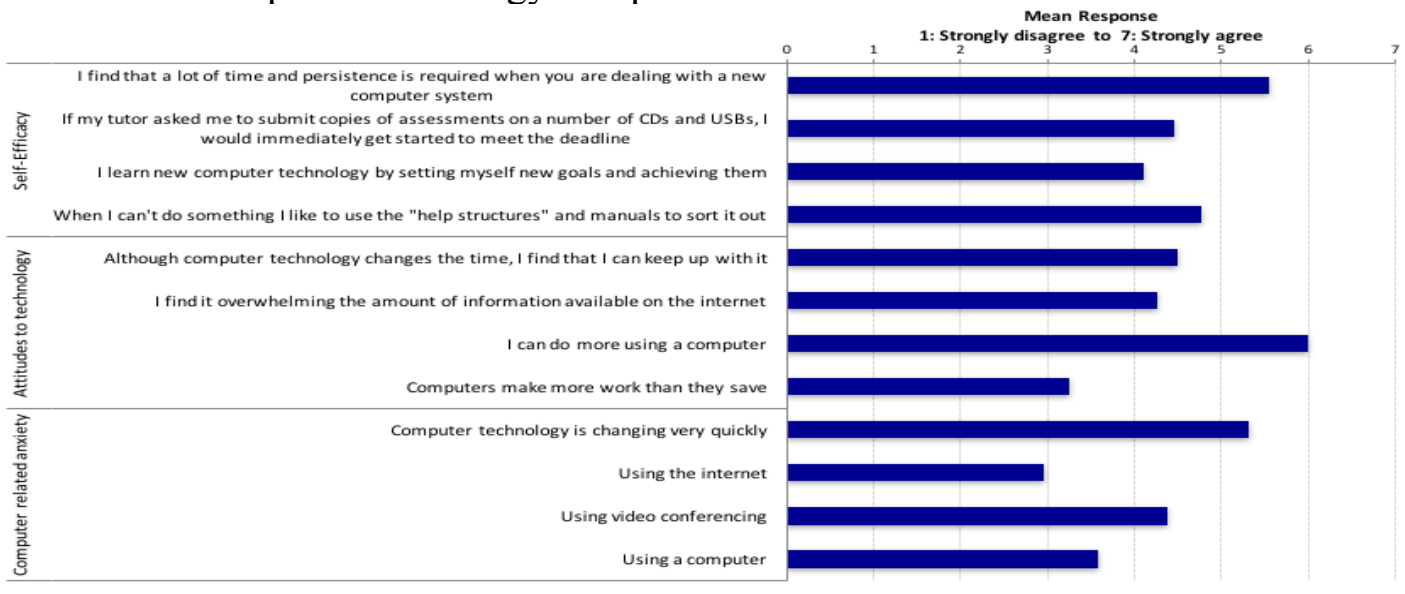

Fig. 1 Selected responses to 12 of the 49 items on the CTUS 
At collection points two through five, participating staff were asked to respond to routine evaluations at the completion of the courses utilising Griffith Student Evaluation of Courses Survey Data. Table 1 presents scores assigned by the two cohorts on a 5-point rating scale. Taken together, these positive scores endorsed the lecture and tutorial formats, the design of websites and online learning features, and overall satisfaction with the learning outcomes of the program.

Table 1 Mean Score for Selected Items

\begin{tabular}{|c|c|c|c|c|c|}
\hline \multirow[t]{2}{*}{ Cohort } & \multirow{2}{*}{$\begin{array}{c}\text { Course } \\
(\% \text { response })\end{array}$} & \multicolumn{4}{|c|}{ Course Evaluation } \\
\hline & & organisation & engagement & teaching \& learning & satisfaction \\
\hline \multirow{4}{*}{ 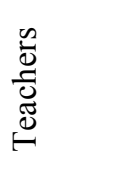 } & Auslan $1(94 \%)$ & 4.2 & 4.7 & 4.5 & 4.1 \\
\hline & Auslan $2(88 \%)$ & 4.6 & 4.5 & 4.4 & 4.4 \\
\hline & Auslan $3(73 \%)$ & 4.1 & 4.3 & 4.3 & 4.2 \\
\hline & Auslan $4(43 \%)$ & 3.8 & 3.8 & 4.0 & 3.8 \\
\hline \multirow{4}{*}{ 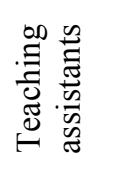 } & Auslan $1(70 \%)$ & 3.6 & 4.3 & 4.1 & 3.9 \\
\hline & Auslan $2(89 \%)$ & 4.0 & 3.8 & 4.0 & 4.0 \\
\hline & Auslan $3(56 \%)$ & 3.6 & 3.4 & 3.8 & 3.6 \\
\hline & Auslan $4(33 \%)$ & 4.3 & 4.3 & 4.3 & 4.3 \\
\hline
\end{tabular}

At collection points two through five, participating staff also responded to an online satisfaction survey with nine Likert-style questions and three open-ended questions related to experienced challenges and benefits that represented items from surveys evaluating web-based professional development programs [7, 8]. Fig. 2 summarises the overall patterns from the group. The first two items, the most positive in response, indicate that staff found the course site easy to navigate - with a clear improvement after the first period. Also they agree that there were good opportunities to interact with the instructor - through various mediums. In line with the comments on Fig. 1, there seemed to be no marked change regarding confidence with the internet, with item 8 "this class has made me feel more comfortable using the internet" showing a neutral level across the four semesters of study. While there was a very clear response to item 9 (people learned as well on-line as in a face-to-face class), this is not surprising, but a number of participating staff also recognised that a fully face-to-face learning environment was not an option.

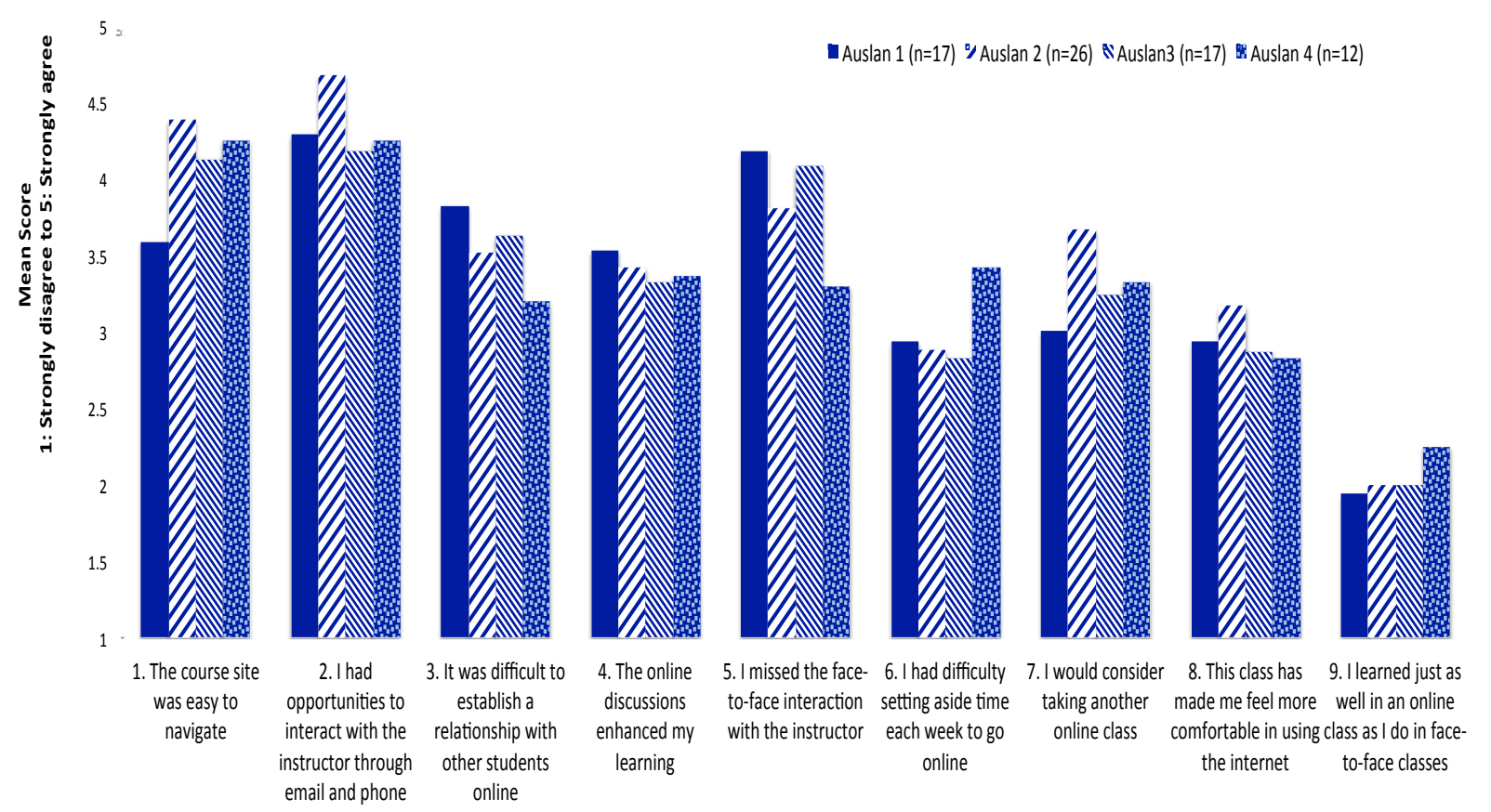

Fig. 2 Participant mean scores to satisfaction survey 


\section{Summary}

When considering the outcomes of the program, which targeted building specific skill capacity in a group of specialised staff, it is important to recognise that the use of technology was a facilitating factor rather than an objective. The inclusion of many geographically isolated teachers and teaching assistants in the program was only possible by the program being completed in mixed-mode delivery. The design included several intensive teaching periods to build a cohesive group and support the use of delivery technologies for learning. At the beginning of the program, participating staff indicated a moderate level of skill and capacity with using computer technologies. At the end of the program, data collection gave a positive picture of outcomes, moderated by a clear preference for the face-to-face environment. Further, a number of graduates demonstrated high quality learning outcomes that would support aspirations for further study. This endorsement by graduates was congruent with the satisfaction expressed by DET (program sponsor) and aligned with the University's expectation of advancing innovations in learning and teaching. Taken together, the approach utilised in this program highlights the pedagogical possibilities that delivery technologies for learning offer in Higher Education.

\section{References}

[1] B. Means, M. Bakia, R. Murphy, Learning Online: What Research Tells Us about Whether, When, and How, London, Routledge, 2014.

[2] M. Gosper, D. Green, M. McNeill, R. Phillips, G. Preston, and K. Woo, The impact of web-based lecture technologies on current and future practices in learning and teaching, Australian Learning and Teaching Council. 2008. Retrieved from http://www.cpd.mq.edu.au/teaching/wblt/overview.htm.

[3] A.L. Brown, Design experiments: Theoretical and methodological challenges in creating complex interventions, Journal of the Learning Sciences. 2 (1992) 141-178.

[4] Design-based Research Collective, Design-based research: An emerging paradigm for educational inquiry, Educational Researcher. 32 (2003) 5-8.

[5] T. Johnston, A. Schembri, Australian Sign Language (Auslan): An introduction to sign language linguistics, London, Cambridge University Press, 2007.

[6] M. Conrad, D. Munro, Relationships between computer self-efficacy, technology, attitudes and anxiety: Development of the Computer Technology Use Scale (CTUS), Journal of Educational Computing Research. 39 (2008) 51-73.

[7] D. Chen, D. Klein, and L. Minor, Interdisciplinary perspectives in early intervention: Professional development in multiple disabilities through distance education, Infants \& Young Children. 22 (2009) 146-158.

[8] S. Rakap, H.A. Jones, and A. Emery, Evaluation of a web-based professional development program (Project ACE) for teachers of children with autism spectrum disorders, Teacher Education and Special Education. 38 (2015) 221-239. 